\section{(6) OPEN ACCESS}

\title{
Frequency and determinants of consistent STI/HIV testing among men who have sex with men testing at STI outpatient clinics in the Netherlands: a longitudinal study
}

\author{
Maartje Visser, ${ }^{1}$ Janneke C M Heijne, ${ }^{1}$ Arjan A Hogewoning, ${ }^{2}$ Fleur van Aar ${ }^{1}$
}

\begin{abstract}
- Additional material is published online only. To view please visit the journal online (http://dx.doi.org/10.1136/ sextrans-2016-052918).

${ }^{1}$ Centre for Infectious Disease Control, National Institute for Public Health and the Environment, Bilthoven, The Netherlands

${ }^{2}$ STI Outpatient Clinic, Public Health Service of Amsterdam, Amsterdam, The Netherlands
\end{abstract}

\section{Correspondence to}

Dr Janneke Heijne, National Institute of Public Health and the Environment, P.O. Box 1, Bilthoven 3720 BA The Netherlands: janneke.heijne@rivm.nl

Received 7 October 2016 Revised 2 December 2016 Accepted 4 January 2017 Published Online First 3 February 2017

\section{ABSTRACT \\ Objectives Men who have sex with men (MSM) are at highest risk for STIs and HIV infections in the Netherlands. However, official guidelines on STI testing among MSM are lacking. They are advised to test for STIs at least every six months, but their testing behaviour is not well known. This study aimed to get insight into the proportion and determinants of consistent 6-monthly STI testing among MSM testing at STI outpatient clinics in the Netherlands. \\ Methods This study included longitudinal surveillance data of STI consultations among MSM from all 26 STI outpatient clinics in the Netherlands between 1 June 2014 and 31 December 2015. Multinomial logistic regression analysis was used to identify determinants of consistent 6-monthly testing compared with single testing and inconsistent testing. Determinants of time between consultations among men with multiple consultations were analysed using a Cox Prentice- Williams-Peterson gap-time model.}

Results A total of 34605 STI consultations of 18634 MSM were included. $8966(48.1 \%)$ men had more than one consultation, and 3516 (18.9\%) men tested consistently 6-monthly. Indicators of high sexual risk behaviour, including having a history of STI, being HIV positive and having more than 10 sex partners, were positively associated with both being a consistent tester and returning to the STI clinic sooner. Men who were notified by a partner or who reported STI symptoms were also more likely to return to the STI clinic sooner, but were less likely to be consistent testers, identifying a group of event-driven testers.

Conclusions The proportion of consistent 6-monthly testers among MSM visiting Dutch STI outpatient clinics was low. Testing behaviour was associated with sexual risk behaviour, but exact motives to test consistently remain unclear. Evidence-based testing guidelines are needed to achieve optimal reductions in STI transmission in the future.

\section{INTRODUCTION}

Men who have sex with men (MSM) are at highest risk for STIs, including HIV, in the Netherlands. ${ }^{1}$ In $2015,68 \%$ of gonorrhoea cases, $90 \%$ of HIV cases and $96 \%$ of syphilis cases diagnosed at STI clinics were among MSM. ${ }^{1}$ Frequent STI/HIV testing could be an effective STI control strategy as it helps detecting (asymptomatic) infections at an earlier stage. This allows earlier treatment and could therefore reduce STI transmission and morbidity. $^{2-4}$

In some countries, guidelines about repeated testing among MSM have been established. The US Center for Disease Control guidelines state that all sexually active MSM need to be tested for HIV, syphilis, gonorrhoea and chlamydia at least annually. ${ }^{5}$ In addition, a 3-monthly to 6-monthly testing interval is recommended for MSM who practice risk behaviours such as having unprotected sex or having multiple (anonymous) partners. ${ }^{5}$ Also in Australia and the UK, guidelines recommend annual testing for all MSM and 3-monthly to 6-monthly testing for MSM practicing risk behaviour. ${ }^{6}$ In the Netherlands, there are no official guidelines for STI/HIV testing among MSM. However, the non-governmental organisation STI AIDS Netherlands recommends all sexually active MSM to test for STI/HIV consistently at least every six months. HIV-positive MSM with casual partners and MSM practising risk behaviour are advised to test 3 -monthly. ${ }^{3}$

Little is known, however, about consistent 6-monthly STI testing behaviour among MSM in the Netherlands. One study by Vriend et al, ${ }^{8}$ using data from the Amsterdam STI clinic only, showed that $36 \%$ of MSM STI clinic visitors returned for a subsequent test within a year. No studies on consistent testing among MSM on a national level have been performed in the Netherlands as longitudinal surveillance data on STI testing were until recently not collected at a national level. In June 2014, an anonymous personal identification (ID) number was added to the data collection of STI clinics in the Netherlands. From this moment onwards, it was possible to get insight in repeated STI testing at the same STI clinic over time on a national level. This study aimed to get insight into the proportion of MSM who consistently tested at Dutch STI outpatient clinics between June 2014 and December 2015. In addition, we aimed to identify independent socio-demographic and behavioural determinants of repeat testing.

\section{METHODS}

Study population

This study used surveillance data of all STI consultations among MSM from all 26 Dutch STI clinics. In the Netherlands, STI clinics provide free and anonymous STI testing for MSM. Longitudinal STI 
Table 1 Baseline characteristics of men who have sex with men aged 14-89 years, who tested at STI clinics in the Netherlands between 1 June 2014 and 31 December 2015

\begin{tabular}{|c|c|}
\hline Baseline characteristics & $\mathrm{N}(\%)$ \\
\hline Total & 18634 \\
\hline \multicolumn{2}{|l|}{ Age (years) } \\
\hline $14-26$ & $4801(25.8)$ \\
\hline $27-35$ & $4383(23.5)$ \\
\hline $36-47$ & $4905(26.3)$ \\
\hline $48+$ & $4545(24.4)$ \\
\hline \multicolumn{2}{|l|}{ Sexual orientation } \\
\hline Homosexual & $15136(81.2)$ \\
\hline Bisexual & 3498 (18.8) \\
\hline \multicolumn{2}{|l|}{ Region of STI clinic } \\
\hline Limburg & $1178(6.3)$ \\
\hline Noord-Holland/Flevoland & 7988 (42.9) \\
\hline Noord-Nederland & $755(4.0)$ \\
\hline Oost-Nederland & $2993(16.1)$ \\
\hline Utrecht & $893(4.8)$ \\
\hline Zeeland/Brabant & $2048(11.0)$ \\
\hline Zuid-Holland Noord & $809(4.3)$ \\
\hline Zuid-Holland Zuid & $1970(10.6)$ \\
\hline \multicolumn{2}{|l|}{ Follow-up time } \\
\hline$\leq 365$ days & $6565(35.2)$ \\
\hline$>365$ days & 12069 (64.8) \\
\hline \multicolumn{2}{|l|}{ Socioeconomic status } \\
\hline High & $6505(34.9)$ \\
\hline Medium & $5150(27.6)$ \\
\hline Low & $5446(29.2)$ \\
\hline Missing values & $1533(8.2)$ \\
\hline \multicolumn{2}{|l|}{ Education level } \\
\hline High & $8422(45.2)$ \\
\hline Low & $4476(24.0)$ \\
\hline Missing values & $5736(30.8)$ \\
\hline \multicolumn{2}{|l|}{ Ethnicity } \\
\hline Dutch & $13384(71.8)$ \\
\hline Western non-Dutch & $1614(8.7)$ \\
\hline Non-Western & $3616(19.4)$ \\
\hline Missing values & $20(0.1)$ \\
\hline \multicolumn{2}{|c|}{ Number of sex partners in the past six months } \\
\hline $0-2$ & $4257(22.8)$ \\
\hline $3-4$ & $4472(24.0)$ \\
\hline $5-9$ & $4426(23.8)$ \\
\hline $10+$ & 4951 (26.6) \\
\hline Missing values & $528(2.8)$ \\
\hline \multicolumn{2}{|l|}{ Condom use at last contact } \\
\hline No & $10562(56.7)$ \\
\hline Yes & $7156(38.4)$ \\
\hline Missing values & $916(4.9)$ \\
\hline \multicolumn{2}{|l|}{ Received partner notification } \\
\hline No & $14442(77.5)$ \\
\hline Yes & $4114(22.1)$ \\
\hline Missing values & $78(0.4)$ \\
\hline \multicolumn{2}{|l|}{ Reported STI symptoms } \\
\hline No & $13732(73.7)$ \\
\hline Yes & $4801(25.8)$ \\
\hline Missing values & $101(0.5)$ \\
\hline \multicolumn{2}{|l|}{ Known HIV positive } \\
\hline No & $16260(87.3)$ \\
\hline Yes & 2221 (11.9) \\
\hline Missing values & $153(0.8)$ \\
\hline
\end{tabular}

Table 1 Continued

\begin{tabular}{lc}
\hline Baseline characteristics & N (\%) \\
\hline GO/CT/SYPH in the past two years & \\
No & $14067(75.5)$ \\
Yes & $3595(19.3)$ \\
Missing values & $972(5.2)$ \\
Commercial sex worker & \\
No & $18049(96.9)$ \\
Yes & $370(2.0)$ \\
Missing values & $215(1.1)$ \\
Client of commercial sex worker & \\
No & $17878(95.9)$ \\
Yes & $534(2.9)$ \\
Missing values & $222(1.2)$ \\
Total N consultations per person & \\
1 & $9668(51.9)$ \\
2 & $4826(25.9)$ \\
3 & $2462(13.2)$ \\
4 & $979(5.2)$ \\
5 & $387(2.1)$ \\
6 or more* & $312(1.7)$ \\
\hline *Maximum nine consultations. & \\
CT, chlamydia; GO, gonorrhoea; SYPH, syphilis. & \\
\end{tabular}

clinic data were available from 1 June 2014 to 31 December 2015. Through a personal ID number, tests performed on the same individual at the same STI clinic could be linked, allowing persons to be followed over time. At each STI consultation, information on demographics, sexual behaviour, STI history of the past two years and STI test results were registered. MSM was defined based on self-reported sexual orientation (homosexual or bisexual) or sexual behaviour (having had sex with men in the past six months). Follow-up time was defined as the number of days between a participant's first consultation and 31 December 2015. Ethical approval for the study was not necessary following Dutch law as the study used routinely collected, anonymous surveillance data.

\section{Exclusion criteria}

Men who tested through Testlab, an online testing service for MSM, ${ }^{9}$ were excluded because ID numbers were not appropriately registered in this group. Through Testlab, MSM can anonymously request an STI test online and go directly to a laboratory for sampling, without having a consultation at an STI clinic first. In case of a positive test, men are referred to the STI clinic for treatment and/or further testing. Furthermore, men with less than six months between their first consultation and 31 December 2015 were excluded as the follow-up time was too short to meet our criteria for consistent testing. As a test of cure for chlamydia and gonorrhoea is no common practice in the Netherlands, and is not recommended by guidelines, STI consultations that took place within 30 days of the previous consultation were deleted. Follow-up consultations after a positive syphilis diagnosis were not considered separate testing episodes, and these follow-up consultations were excluded.

\section{Definitions}

The main outcome of interest was testing frequency, categorised into consistent 6-monthly testing, inconsistent testing and single testing. Consistent 6-monthly testers were defined as men who 
had a maximum of 7 months (213 days) between each of their consecutive tests, and between their last test and end of follow-up (31 December 2015). We used the 1-month margin to ensure that a person would not be regarded an inconsistent tester if he returned to the STI clinic shortly after the 6-month interval. Inconsistent testers were all participants who did have multiple consultations, but who did have more than 7 months between consecutive consultations or end of follow-up. Single testers were all participants who had only one consultation during the follow-up time.

\section{Statistical analyses}

First, the proportions of consistent, inconsistent and single testers were determined. To identify determinants of consistent 6-monthly testing, multinomial multivariable logistic regression analysis was used using the characteristics of MSM on their first consultation during the study period. Two logistic regression models were constructed; one assessed characteristics of consistent 6-monthly testers and single testers compared with inconsistent testers. The other model compared consistent and inconsistent testers to the single testers.

To analyse determinants of time between subsequent consultations, a Cox Prentice-Williams-Peterson (PWP) gap-time model was used. The PWP model allows and corrects for multiple consultations occurring within the same person, while taking the order of evens into account by stratifying the analysis based on the prior number of events during follow-up. ${ }^{10}{ }^{11}$ Due to this stratification, estimates can become unreliable if the number of persons within strata becomes too small. ${ }^{12}$ Therefore, only data up to and including the fifth consultation were used in the PWP model. In this analysis, only repeated tests were used, with the subsequent consultation being the outcome and the number of days leading up to that consultation the survival time.

Both the logistic regression and the Cox analyses included demographic and sexual behavioural variables as possible determinants of testing behaviour. Age was not normally distributed and therefore included categorically, using quartiles. Ethnicity was determined based on country of birth of both the participant and his parents, according to the definition of Statistics Netherlands. ${ }^{13}$ We categorised participants into three groups: Dutch (participant and both parents born in the Netherlands), Western non-Dutch (first-generation and second-generation migrants from West European countries, North America and Australia) and non-Western (first-generation and secondgeneration migrants from all other countries). Socioeconomic status (SES) was determined by participants' postal code (four digits). This measure of SES is developed by the Netherlands institute for social research and is an average of, for example, income and employment status of the inhabitants of each postal code area. ${ }^{14}$ Education level was included in two categories. Low education level included no education, primary education only and vocational education. High level included all other education levels.

Other variables included in analyses were sexual orientation, region of STI clinic, follow-up time, number of sex partners in the past six months, condom use at last sexual contact, having received partner notification, reported STI symptoms, being known HIV positive, having had chlamydia, gonorrhoea or syphilis in the past two years, being a commercial sex worker and being a client of a commercial sex worker. The Cox regression also included positive diagnosis for chlamydia, gonorrhoea, syphilis and HIV at both the present and the previous consultation. For variables with more than $5 \%$ missing values, missing values were included in the analyses as a separate category.
In all regression analyses, both univariable and multivariable analyses were performed. Variables were eligible for inclusion in the multivariable models if they were associated with testing behaviour in univariable analyses with a $\mathrm{p}$ value $\leq 0.1$. The multivariable models were constructed using backward elimination, using a significance level of 0.05 . In the Cox analysis, effect modification by consistent testing behaviour was examined by adding interaction terms in univariable analysis for all variables that remained in the multivariable model. All analyses were performed using Stata V.13 (StataCorp, College Station, Texas, USA).

\section{RESULTS}

\section{Study population}

Between 1 June 2014 and 31 December 2015, a total of 50275 STI consultations of 31359 MSM included a personal ID number. In total, 4563 men (with 6274 consultations) were excluded because they tested through Testlab, 8162 men (with 8961 consultations) because they had a follow-up time of less than 6 months and 435 consultations were excluded because they were within 30 days of the previous consultation. After exclusions, 34605 consultations of 18634 MSM remained available for analyses.

The median age of the MSM was 36 (IQR 26-47) (table 1). Most men were homosexual (81.2\%) and of Dutch ethnicity (71.8\%). The median time between consultations was 159 days (IQR 97-217). Among all MSM, 8966 (48.1\%) had two or more consultations, and 3516 men (18.9\%) met our criteria of consistent 6-monthly testing.

\section{Determinants of consistent testing}

The strongest positive predictor of consistent testing was having had more than 10 sex partners in the past six months: the odds of being a consistent tester were 1.56 times higher for men who had more than 10 partners in the past six months compared with men with $0-2$ partners (95\% CI 1.36 to 1.80 ) (table 2). Furthermore, men were more likely to be a consistent tester if they had a low education level, were HIV positive or had an STI in the past two years. Men were less likely to be a consistent tester if they were bisexual (aOR 0.67 (95\% CI 0.58 to 0.78 )). Men with a longer follow-up time or reporting STI symptoms were also less likely to be consistent testers. In the model with single testers as reference category, the same determinants for consistent testing were found, though the associations were stronger and more variables were significant (see online supplementary table S1).

\section{Determinants of time between consultations}

The Cox analyses were stratified by consistent testing behaviour as this was found to be an effect modifier (table 3). For both strata, men were more likely to return for a subsequent consultation sooner if they received partner notification, reported STI symptoms, were HIV positive or were diagnosed with chlamydia, gonorrhoea or syphilis at their previous consultation. In addition, having had more sex partners was also associated with returning to the STI clinic sooner among consistent testers, but this was not found among inconsistent testers. Among consistent testers, stronger effects were found for partner notification (adjusted HR (aHR) 1.32 (95\% CI 1.23 to 1.40)), STI symptoms (aHR 1.24 (95\% CI 1.16 to 1.31$)$ ) and being HIV positive (aHR 1.31 (95\% CI 1.21 to 1.40)) than among inconsistent testers. 
Table 2 Proportion and determinants of single and consistent testing compared to inconsistent testing among men who have sex with men aged 14-89 years, who tested at STI clinics in the Netherlands between 1 June 2014 and 31 December 2015 using baseline consultations $(\mathrm{N}=18$ 634)

\begin{tabular}{|c|c|c|c|c|c|c|c|c|c|c|}
\hline & \multicolumn{2}{|c|}{$\begin{array}{l}\text { Inconsistent } \\
\text { testers }\end{array}$} & \multicolumn{4}{|c|}{ Single testers } & \multicolumn{4}{|c|}{ Consistent (6-monthly) testers } \\
\hline & $\mathbf{n}$ & $\%$ & $\mathbf{n}$ & $\%$ & $\begin{array}{l}\text { Crude } \\
\text { OR (95\% Cl) }\end{array}$ & $\begin{array}{l}\text { Adjusted } \\
\text { OR ( } 95 \% \mathrm{Cl})\end{array}$ & $\mathbf{n}$ & $\%$ & $\begin{array}{l}\text { Crude } \\
\text { OR }(95 \% \mathrm{Cl})\end{array}$ & $\begin{array}{l}\text { Adjusted } \\
\text { OR ( } 95 \% \mathrm{Cl})\end{array}$ \\
\hline Total & 5450 & 29.2 & 9668 & 51.9 & & & 3516 & 18.9 & & \\
\hline \multicolumn{11}{|l|}{ Age (years) $\dagger$} \\
\hline $14-26$ & 1295 & 27.0 & 2746 & 57.2 & 1 & - & 760 & 15.8 & 1 & - \\
\hline $27-35$ & 1330 & 30.3 & 2249 & 51.3 & $0.80(0.73-0.88)$ & - & 804 & 18.3 & $1.03(0.91-1.17)$ & - \\
\hline $36-47$ & 1517 & 30.9 & 2335 & 47.6 & $0.73(0.66-0.80)$ & - & 1053 & 21.5 & $1.18(1.05-1.33)$ & - \\
\hline $48+$ & 1308 & 28.8 & 2338 & 51.4 & $0.84(0.77-0.93)$ & - & 899 & 19.8 & $1.17(1.04-1.32)$ & - \\
\hline \multicolumn{11}{|l|}{ Reported sexual orientation } \\
\hline Homosexual & 4611 & 30.5 & 7410 & 49.0 & 1 & 1 & 3115 & 20.6 & 1 & 1 \\
\hline Bisexual & 839 & 24.0 & 2258 & 64.5 & $1.68(1.54-1.83)$ & $1.54^{* *}(1.39-1.70)$ & 401 & 11.5 & $0.71(0.62-0.80)$ & $0.67^{* *}(0.58-0.78)$ \\
\hline \multicolumn{11}{|l|}{ Region of STI clinic $\ddagger$} \\
\hline Limburg & 410 & 34.8 & 544 & 46.2 & 1 & - & 224 & 19.0 & 1 & - \\
\hline Noord-Holland/Flevoland & 2414 & 30.2 & 3744 & 46.9 & $1.17(1.02-1.34)$ & - & 1830 & 22.9 & $1.39(1.17-1.65)$ & - \\
\hline Noord-Nederland & 194 & 25.7 & 480 & 63.6 & $1.86(1.51-2.30)$ & - & 81 & 10.7 & $0.76(0.56-1.04)$ & - \\
\hline Oost-Nederland & 981 & 32.8 & 1487 & 49.7 & $1.14(0.98-1.33)$ & - & 525 & 17.5 & $0.98(0.81-1.19)$ & - \\
\hline Utrecht & 221 & 24.7 & 591 & 66.2 & $2.02(1.65-2.46)$ & - & 81 & 9.1 & $0.67(0.50-0.91)$ & - \\
\hline Zeeland/Brabant & 582 & 28.4 & 1132 & 55.3 & $1.47(1.25-1.73)$ & - & 334 & 16.3 & $1.05(0.85-1.30)$ & - \\
\hline Zuid-Holland Noord & 101 & 12.5 & 526 & 65.0 & $3.93(3.06-5.03)$ & - & 182 & 22.5 & $3.30(2.46-4.42)$ & - \\
\hline Zuid-Holland Zuid & 547 & 27.8 & 1164 & 59.1 & $1.60(1.36-1.89)$ & - & 259 & 13.1 & $0.87(0.70-1.08)$ & - \\
\hline \multicolumn{11}{|l|}{ Follow-up time } \\
\hline$\leq 365$ days & 796 & 12.1 & 4455 & 67.9 & 1 & 1 & 1314 & 20.0 & 1 & 1 \\
\hline$>365$ days & 4654 & 38.6 & 5213 & 43.2 & $0.20(0.18-0.22)$ & $0.23^{* *}(0.21-0.26)$ & 2202 & 18.2 & $0.29(0.26-0.32)$ & $0.25^{* *}(0.22-0.28)$ \\
\hline \multicolumn{11}{|l|}{ Socio-economic status } \\
\hline High & 2054 & 31.6 & 3215 & 49.4 & 1 & 1 & 1236 & 19.0 & 1 & 1 \\
\hline Medium & 1488 & 28.9 & 2680 & 52.0 & $1.15(1.06-1.25)$ & $0.92(0.84-1.01)$ & 982 & 19.1 & $1.10(0.99-1.22)$ & $0.96(0.89-1.08)$ \\
\hline Low & 1510 & 27.7 & 2882 & 52.9 & $1.22(1.12-1.33)$ & $0.90 *(0.82-0.99)$ & 1054 & 19.4 & $1.16(1.04-1.29)$ & $0.93(0.83-1.04)$ \\
\hline Missing values & 398 & 26.0 & 891 & 58,1 & $1.43(1.26-1.63)$ & $1.31^{* *}(1.12-1.51)$ & 244 & 15.9 & $1.02(0.86-1.21)$ & $0.89(0.73-1.07)$ \\
\hline \multicolumn{11}{|l|}{ Education level } \\
\hline High & 2192 & 26.0 & 4858 & 57.7 & 1 & 1 & 1372 & 16.3 & 1 & 1 \\
\hline Low & 1145 & 25.6 & 2517 & 56.2 & $0.99(0.91-1.08)$ & $0.98(0.89-1.08)$ & 814 & 18.2 & $1.14(1.02-1.27)$ & $1.16^{*}(1.02-1.31)$ \\
\hline Missing values & 2113 & 36.8 & 2293 & 40.0 & $0.49(0.45-0.53)$ & $0.73^{* *}(0.88-0.80)$ & 1330 & 23.2 & $1.01(0.91-1.11)$ & $1.28^{* *}(1.15-1.43)$ \\
\hline \multicolumn{11}{|l|}{ Ethnicity } \\
\hline Dutch & 3909 & 29.2 & 7009 & 52.4 & 1 & 1 & 2466 & 18.4 & 1 & 1 \\
\hline Western non-Dutch & 470 & 29.1 & 852 & 52.8 & $1.01(0.90-1.14)$ & $1.12(0.98-1.28)$ & 292 & 18.1 & $0.99(0.84-1.15)$ & $0.93(0.79-1.10)$ \\
\hline Non-Western & 1068 & 29.5 & 1794 & 49.6 & $0.94(0.86-1.02)$ & $0.90 *(0.82-0.99)$ & 754 & 20.9 & $1.12(1.01-1.24)$ & $1.08(0.96-1.21)$ \\
\hline Missing values & 3 & 15.0 & 13 & 65.0 & & & 4 & 20.0 & & \\
\hline \multicolumn{11}{|c|}{ Number of sex partners in the past six months } \\
\hline $0-2$ & 959 & 22.5 & 2789 & 65.5 & 1 & 1 & 509 & 12.0 & 1 & 1 \\
\hline $3-4$ & 1238 & 27.7 & 2523 & 56.4 & $0.70(0.63-0.77)$ & $0.70^{* *}(0.62-0.78)$ & 711 & 15.9 & $1.08(0.94-1.25)$ & $1.14(0.98-1.33)$ \\
\hline $5-9$ & 1437 & 32.5 & 2141 & 48.4 & $0.51(0.46-0.57)$ & $0.52^{* *}(0.47-0.58)$ & 848 & 19.2 & $1.11(0.97-1.28)$ & $1.15(0.99-1.33)$ \\
\hline $10+$ & 1640 & 33.1 & 1981 & 40.0 & $0.42(0.38-0.46)$ & $0.44^{* *}(0.39-0.49)$ & 1330 & 26.9 & $1.53(1.34-1.74)$ & $1.56^{* *}(1.36-1.80)$ \\
\hline Missing values & 176 & 33.3 & 234 & 44.3 & & & 118 & 22.4 & & \\
\hline \multicolumn{11}{|l|}{ Condom use at last contact } \\
\hline No & 2998 & 28.4 & 5701 & 54.0 & 1 & 1 & 1863 & 17.6 & 1 & 1 \\
\hline Yes & 2229 & 31.1 & 3442 & 48.1 & $0.81(0.76-0.87)$ & $0.88^{*}(0.81-0.95)$ & 1485 & 20.8 & $1.07(0.98-1.17)$ & $1.05(0.95-1.15)$ \\
\hline Missing values & 223 & 24.4 & 525 & 57.3 & & & 168 & 18.3 & & \\
\hline \multicolumn{11}{|l|}{ Received partner notification } \\
\hline No & 4277 & 29.6 & 7424 & 51.4 & 1 & 1 & 2741 & 19.0 & 1 & 1 \\
\hline Yes & 1151 & 28.0 & 2196 & 53.4 & $1.10(1.01-1.19)$ & $1.14^{*}(1.04-1.25)$ & 767 & 18.6 & $1.04(0.94-1.15)$ & $0.95(0.85-1.06)$ \\
\hline Missing values & 22 & 28.2 & 48 & 61.5 & & & 8 & 10.3 & & \\
\hline \multicolumn{11}{|l|}{ Reported STI symptoms } \\
\hline No & 3999 & 29.1 & 7068 & 51.5 & 1 & 1 & 2665 & 19.4 & 1 & 1 \\
\hline Yes & 1427 & 29.7 & 2533 & 52.8 & $1.00(0.93-1.08)$ & $1.06(0.97-1.15)$ & 841 & 17.5 & $0.88(0.80-0.98)$ & $0.78^{* *}(0.71-0.87)$ \\
\hline Missing values & 24 & 23.8 & 67 & 66.3 & & & 10 & 9.9 & & \\
\hline
\end{tabular}


Table 2 Continued

\begin{tabular}{|c|c|c|c|c|c|c|c|c|c|c|}
\hline & \multicolumn{2}{|c|}{$\begin{array}{l}\text { Inconsistent } \\
\text { testers }\end{array}$} & \multicolumn{4}{|c|}{ Single testers } & \multicolumn{4}{|c|}{ Consistent (6-monthly) testers } \\
\hline & n & $\%$ & n & $\%$ & $\begin{array}{l}\text { Crude } \\
\text { OR (95\% Cl) }\end{array}$ & $\begin{array}{l}\text { Adjusted } \\
\text { OR ( } 95 \% \mathrm{Cl})\end{array}$ & n & $\%$ & $\begin{array}{l}\text { Crude } \\
\text { OR (95\% Cl) }\end{array}$ & $\begin{array}{l}\text { Adjusted } \\
\text { OR (95\% Cl) }\end{array}$ \\
\hline \multicolumn{11}{|l|}{ Known HIV positive } \\
\hline No & 4674 & 28.7 & 8689 & 53.4 & 1 & 1 & 2897 & 17.8 & 1 & 1 \\
\hline Yes & 744 & 33.5 & 867 & 39.0 & $0.63(0.56-0.70)$ & $0.95(0.84-1.07)$ & 610 & 27.5 & $1.32(1.18-1.49)$ & $1.26 *(1.10-1.43)$ \\
\hline Missing values & 32 & 20.9 & 112 & 73.2 & & & 9 & 5.9 & & \\
\hline \multicolumn{11}{|c|}{ GO/CT/SYPH in the past two years } \\
\hline No & 3861 & 27.5 & 7811 & 55.5 & 1 & 1 & 2395 & 17.0 & 1 & 1 \\
\hline Yes & 1390 & 38.7 & 1200 & 33.4 & $0.43(0.39-0.47)$ & $0.56^{* *}(0.51-0.62)$ & 1005 & 28.0 & $1.17(1.06-1.28)$ & 1.31 ** $(1.18-1.45)$ \\
\hline Missing values & 199 & 20.5 & 657 & 67.6 & & & 116 & 11.9 & & \\
\hline \multicolumn{11}{|c|}{ Commercial sex worker‡ } \\
\hline No & 5297 & 29.3 & 9364 & 51.9 & 1 & - & 3388 & 18.8 & 1 & - \\
\hline Yes & 100 & 27.0 & 188 & 50.8 & $1.06(0.83-1.36)$ & - & 82 & 22.2 & $1.28(0.95-1.72)$ & - \\
\hline Missing values & 53 & 24.6 & 116 & 54.0 & & & 46 & 21.4 & & \\
\hline \multicolumn{11}{|c|}{ Client of commercial sex worker‡ } \\
\hline No & 5281 & 29.6 & 9195 & 51.4 & 1 & - & 3402 & 19.0 & 1 & - \\
\hline Yes & 112 & 21.0 & 347 & 65.0 & $1.78(1.43-2.21)$ & - & 75 & 14.0 & $1.04(0.77-1.40)$ & - \\
\hline Missing values & 57 & 25.7 & 126 & 56.7 & & & 39 & 17.6 & & \\
\hline
\end{tabular}

\section{DISCUSSION}

We observed that consistent 6-monthly testing is relatively uncommon among MSM visiting Dutch STI clinics: 19\% met our criteria of consistent testing during a 1.5-year follow-up period. Having a history of STI in the past two years, being HIV positive and having more than 10 sex partners in the past six months were positively associated with both consistent 6-monthly testing and returning to the STI clinic sooner. Men with a low education level were also more often consistent testers. Having STI symptoms was negatively associated with consistent 6-monthly testing, while we found that men experiencing STI symptoms or having received partner notification were more likely to return to the STI clinic sooner.

This is the first longitudinal study on STI testing behaviour using data from all STI clinics in the Netherlands. Because national surveillance data were used, the study sample was very large $(\mathrm{N}=18$ 634). There are several limitations. First, our estimates of consistent testing were based on a limited follow-up period of 18 months. There was a negative association between follow-up time and consistent testing in the analysis, indicating that the proportion of consistent testers might become lower when using a longer study period. Second, only consultations performed by the same individual at the same STI clinic could be linked by an ID number. Hence, consultations of the same individual at other STI clinics or at other testing facilities (such as general practitioners or Testlab) were not included. This could have resulted in an underestimation of consistent testing. An internet survey executed among MSM in 2013 found that most participating men (54.4\%) had their last HIV test at an STI clinic, ${ }^{15}$ but it remains unknown whether and how often MSM switch between STI clinic services and other testing facilities. However, since testing at STI clinics is free of charge, we expect that switching to other (paid) services was not common. Third, STI tests performed at HIV treatment centres were not included in this study. However, HIV-positive MSM in care are offered yearly syphilis and (if practising risk behaviour) also hepatitis C testing, but are referred to STI clinics for testing for other STIs. Therefore, we do not think that this has greatly influenced our results. Last, we used routinely collected surveillance data, which included very limited information on sexual behaviour. Hence, we used HIV status, low education level and number of sex partners in the previous six months as proxies for sexual (high) risk behaviour. ${ }^{16-18}$ Furthermore, there were many missing values for SES and education level, but loss of data was restricted by including missing values in the analyses as a separate category.

Few other studies on consistent testing behaviour among MSM have been performed. ${ }^{8}{ }^{19-21}$ The design and methods used to identify determinants of testing behaviour and the definitions of consistent testing differed greatly between all studies, making comparisons of results difficult. ${ }^{8}{ }^{19-21}$ A consistent finding in all studies, including ours, was that a minority of MSM tested according to guidelines; in the Netherlands, Australia and the UK, the estimated proportion of MSM testing at least 12 -monthly ranged between $33 \%$ and $36 \%{ }^{8} 1921$ compared with $19 \%$ testing 6 -monthly in our study. Consistent with all other studies, ${ }^{8}{ }^{19-21}$ we found that having had more than 10 sex partners in the preceding six months was associated with more frequent STI testing. Other determinants of more frequent STI testing that corresponded with our findings were being homosexual (as opposed to being bisexual), ${ }^{8}{ }^{20}$ being HIV-positive ${ }^{21}$ and having a history of STI(s). ${ }^{20}$ Men who reported having casual sex partners were also more frequently testing in two other studies. ${ }^{8} 19$ However, in our study, information on type of partner was not available and could therefore not be included in the analyses.

The exact motivations among MSM to test consistently remain unclear. Our results identified two different types of 
Table 3 Determinants of time between consecutive consultations among men who have sex with men aged 14-89 years, who tested multiple times at STI clinics in the Netherlands between 1 June 2014 and 31 December 2015; Cox Prentice-Williams-Peterson gap-time models, stratified for inconsistent and consistent testers

\begin{tabular}{|c|c|c|c|c|}
\hline & \multicolumn{2}{|c|}{ Inconsistent testers } & \multicolumn{2}{|c|}{ Consistent (6-monthly) testers } \\
\hline & $\begin{array}{l}\text { Crude } \\
\text { HR }(95 \% \mathrm{Cl})\end{array}$ & $\begin{array}{l}\text { Adjusted } \\
\text { HRt }(95 \% \mathrm{Cl})\end{array}$ & $\begin{array}{l}\text { Crude } \\
\text { HR }(95 \% \mathrm{CI})\end{array}$ & $\begin{array}{l}\text { Adjusted } \\
\text { HR†ף }(95 \% \mathrm{Cl})\end{array}$ \\
\hline \multicolumn{5}{|c|}{ Number of sex partners in the past six months } \\
\hline $0-2$ & 1 & 1 & 1 & 1 \\
\hline $3-4$ & $0.87(0.81-0.93)$ & $0.87 * *(0.81-0.94)$ & $1.10(1.02-1.19)$ & $1.10 *(1.01-1.19)$ \\
\hline $5-9$ & $0.91(0.85-0.98)$ & $0.92 *(0.86-0.99)$ & $1.11(1.03-1.20)$ & $1.11^{*}(1.03-1.20)$ \\
\hline $10+$ & $0.92(0.86-0.98)$ & $0.93 *(0.86-0.99)$ & $1.19(1.11-1.27)$ & $1.17^{* *}(1.08-1.26)$ \\
\hline \multicolumn{5}{|c|}{ Condom use at last contact $\ddagger$} \\
\hline No & 1 & - & 1 & - \\
\hline Yes & $0.96(0.92-1.00)$ & - & $0.96(0.91-1.00)$ & - \\
\hline \multicolumn{5}{|c|}{ Received partner notification } \\
\hline No & 1 & 1 & 1 & 1 \\
\hline Yes & $1.15(1.09-1.22)$ & $1.11 * *(1.05-1.18)$ & $1.44(1.35-1.53)$ & $1.32^{* *}(1.23-1.40)$ \\
\hline \multicolumn{5}{|c|}{ Reported STI symptoms } \\
\hline No & 1 & 1 & 1 & 1 \\
\hline Yes & $1.15(1.09-1.21)$ & $1.09 * *(1.04-1.16)$ & $1.40(1.32-1.48)$ & $1.24^{* *}(1.16-1.31)$ \\
\hline \multicolumn{5}{|c|}{ Known HIV positive } \\
\hline No & 1 & 1 & 1 & 1 \\
\hline Yes & $1.15(1.08-1.22)$ & $1.10 *(1.03-1.17)$ & $1.42(1.33-1.51)$ & $1.31 * *(1.21-1.40)$ \\
\hline \multicolumn{5}{|c|}{ Commercial sex worker $\ddagger$} \\
\hline No & 1 & - & 1 & - \\
\hline Yes & $1.01(0.86-1.20)$ & - & $1.29(1.12-1.49)$ & - \\
\hline \multicolumn{5}{|c|}{ Client of commercial sex worker§ } \\
\hline No & 1 & - & 1 & - \\
\hline Yes & $0.97(0.85-1.11)$ & - & $1.11(0.95-1.30)$ & - \\
\hline \multicolumn{5}{|c|}{ Positive chlamydia diagnosis§ } \\
\hline No & 1 & - & 1 & - \\
\hline Yes & $0.95(0.88-1.02)$ & - & $1.20(1.11-1.30)$ & - \\
\hline \multicolumn{5}{|c|}{ Positive gonorrhoea diagnosisł } \\
\hline No & 1 & - & 1 & - \\
\hline Yes & $1.06(0.99-1.14)$ & - & $1.31(1.22-1.41)$ & - \\
\hline \multicolumn{5}{|c|}{ Positive syphilis diagnosis§ } \\
\hline No & 1 & - & 1 & - \\
\hline Yes & $1.06(0.92-1.21)$ & - & $1.11(0.98-1.26)$ & - \\
\hline \multicolumn{5}{|c|}{ Positive HIV diagnosis§ } \\
\hline No & 1 & - & 1 & - \\
\hline Yes & $0.96(0.69-1.34)$ & - & $1.12(0.79-1.60)$ & - \\
\hline \multicolumn{5}{|c|}{ Positive chlamydia diagnosis at previous consult } \\
\hline No & 1 & 1 & 1 & 1 \\
\hline Yes & $1.16(1.08-1.25)$ & $1.11 *(1.03-1.20)$ & $1.21(1.13-1.30)$ & $1.08^{*}(1.00-1.17)$ \\
\hline \multicolumn{5}{|c|}{ Positive gonorrhoea diagnosis at previous consult } \\
\hline No & 1 & 1 & 1 & 1 \\
\hline Yes & $1.20(1.11-1.29)$ & $1.13^{*}(1.04-1.23)$ & $1.27(1.18-1.36)$ & $1.09 *(1.01-1.18)$ \\
\hline \multicolumn{5}{|c|}{ Positive syphilis diagnosis at previous consult } \\
\hline No & 1 & - & 1 & - \\
\hline Yes & $1.21(1.08-1.35)$ & - & $1.22(1.08-1.37)$ & - \\
\hline \multicolumn{5}{|c|}{ Positive HIV diagnosis at previous consult§ } \\
\hline No & 1 & - & 1 & - \\
\hline Yes & $0.97(0.76-1.22)$ & - & $0.97(0.69-1.35)$ & - \\
\hline \multicolumn{5}{|c|}{$\begin{array}{l}{ }^{*} p \text { Value }<0.05 . \\
{ }_{*} p \text { Value }<0.001 \text {. } \\
\text { †Adjusted for age, region of STI clinic and socioeconomic status as well. } \\
\ddagger \text { Excluded from multivariable analysis during backward elimination. } \\
\text { §Not included in multivariable analysis due to low significance univariable analysis ( } p \text { value }>0.1 \text { ). } \\
\text { ๆExample of interpretation: consistent testers who received partner notification were } 1.32 \text { times more likely to return to the STI clinic at any point in time compared with consistent } \\
\text { testers who did not receive partner notification. }\end{array}$} \\
\hline
\end{tabular}


testing behaviour: consistent testing and event-driven testing. Men tested more often consistently when belonging to groups associated with an increased, long-term risk for STI; that is, being HIV positive, ${ }^{16}{ }^{18}$ having a low education level, ${ }^{16}$ having a history of STI or having had more than 10 partners in the past six months. ${ }^{17} 22$ We argue that due to this increased risk these MSM are more motivated to visit the STI clinic consistently compared with MSM practising lower risk behaviour. However, it is also possible that this is a consequence of STI clinic practices as men who are at higher sexual risk might be more often encouraged to test consistently. The other testing behaviour identified was event-driven testing; we found that STI symptoms and receiving partner notification were both strongly associated with returning to the STI clinic sooner but not with consistent testing. These are indicators of a present STI infection, and not necessarily of long-term high-risk behaviour. ${ }^{23}{ }^{24}$ Hence, one could argue that long-term high sexual risk, as, for example, indicated by having a history of STI, might be a main contributing factor in predicting consistent testing behaviour as opposed to short-term risk factors such as receiving partner notification or having STI symptoms, which seem to contribute more to an event-driven testing behaviour.

Our results show that the proportion of MSM who test consistently 6 -monthly over a 1.5 -year period at the STI clinic is low (19\%). This raises the question whether consistent 6-monthly testing over a longer period of time, and for all MSM, is an achievable goal, and whether this generalised advice is applicable to all MSM. MSM likely change their sexual behaviour over time, experiencing periods of high and low risk, and hence often do not have a need of consistent STI testing. ${ }^{25} 26$ The use of personal, differentiated testing guidelines, taking into account individual risks and behaviours, could therefore be more fitting.

The STI AIDS Netherlands recommendations ${ }^{3}$ of consistent 6-monthly testing for all sexually active MSM are currently being modified into an official guideline. This guideline will probably also include 3-monthly testing for MSM at highest risk of HIV infection. However, evidence on the optimal testing frequency to interrupt transmission among different risk groups is lacking, and present guidelines differ among countries. Mathematical modelling studies on the impact of testing frequency among MSM have shown that an increase in STI testing would decrease the incidence of syphilis and HIV. ${ }^{27-29}$ In order to inform Dutch guidelines, modelling studies determining the optimal testing frequency to interrupt STI and HIV transmission for different risk groups combined with cost-effectiveness analyses for the Dutch situation are urgently needed. In addition, more research into determinants of testing behaviour and motives among MSM to test consistently should be conducted. Increased knowledge on reasons for testing will help define starting points for the development of tailored testing advices and interventions to increase STI testing according to guidelines.

Altogether, the present recommendation for all sexually active MSM to test consistently every six months over a 1.5 -year follow-up is not well adhered to. Testing behaviour was associated with certain sexual risk behaviours, but exact motives to test consistently remain unclear. The current results highlight the importance of developing clear, evidence-based and differentiated (based on sexual risk behaviour) guidelines to be able to evaluate them properly in the future and to achieve optimal reductions in STI transmission.

\section{Key messages}

- Men who have sex with men (MSM) in the Netherlands are advised to test for STIs every six months, but no official guidelines exist.

- Among MSM visiting STI clinics, $19 \%$ tested consistently every six months between June 2014 and December 2015.

- Being HIV positive, having a history of STI or $>10$ partners in the previous six months was associated with consistent and more frequent STI-testing.

- Clear evidence-based testing guidelines are needed to achieve optimal reductions in STI transmission in the future.

\section{Handling editor Jackie A Cassell}

Acknowledgements The authors thank Marianne van der Sande and Birgit van Benthem for their constructive comments on the manuscript.

Contributors MV, JCMH, and FvA designed the study. MV analysed the data and drafted the manuscript. All authors contributed to the interpretation of the results, commented on the manuscript and approved the final version.

Competing interests None declared.

Provenance and peer review Not commissioned; externally peer reviewed.

Open Access This is an Open Access article distributed in accordance with the Creative Commons Attribution Non Commercial (CC BY-NC 4.0) license, which permits others to distribute, remix, adapt, build upon this work non-commercially, and license their derivative works on different terms, provided the original work is properly cited and the use is non-commercial. See: http://creativecommons.org/ licenses/by-nc/4.0/

\section{REFERENCES}

1 van den Broek IVF, van Aar F, van Oeffelen AAM, et al. Sexually transmitted infections in the Netherlands in 2015. Bilthoven: National Institute for Public Health and the Environment (RIVM), 2016

2 Patel RR, Patel $\mathrm{S}$, Clarke $\mathrm{E}$, et al. Guidance and practice on frequency of HIV and sexually transmitted infection testing in men who have sex with men-what is the European situation? Int J STD AIDS 2014;25:213-18.

3 SOA AIDS Nederland. Onder controle: strategie voor de aanpak van soa's en hiv onder MSM in Nederland 2013-2018. SOA AIDS Nederland, 2013.

4 Wilson DP, Hoare A, Regan DG, et al. Importance of promoting HIV testing for preventing secondary transmissions: modelling The Australian HIV epidemic among men who have sex with men. Sex Health 2009;6:19-33.

5 Workowski KA, Bolan GA, Centers for Disease Control Prevention. Sexually transmitted diseases treatment guidelines, 2015. MMWR Recomm Rep 2015;64:1-137.

6 Templeton DJ, Read P, Varma R, et al. Australian sexually transmissible infection and HIV testing guidelines for asymptomatic men who have sex with men 2014: a review of the evidence. Sex Health 2014;11:217-29.

7 National Institute for Health Care and Excellence (NICE). HIV testing: increasing uptake among people who may have undiagnosed HIV (Joint HICE and Public Health England guideline) (NG60). December 2016. nice.org.uk/guidance/ng60 (accessed 26 Jan 2017).

8 Vriend HJ, Stolte IG, Heijne JC, et al. Repeated STI and HIV testing among HIV-negative men who have sex with men attending a large STI clinic in Amsterdam: a longitudinal study. Sex Transm Infect 2015:91:294-9.

9 Man tot man project, Testlab. https://mantotman.nl/en/testing-and-vaccination/ testlab-your-test/package-tests-and-procedure (accessed 29 Nov 2016).

10 Amorim LD, Cai J. Modelling recurrent events: a tutorial for analysis in epidemiology. Int J Epidemiol 2015;44:324-33.

11 Pandeya N, Purdie DM, Green A, et al. Repeated occurrence of basal cell carcinoma of the skin and multifailure survival analysis: follow-up data from the Nambour Skin Cancer Prevention Trial. Am J Epidemiol 2005;161:748-54.

12 Kelly PJ, Lim LL. Survival analysis for recurrent event data: an application to childhood infectious diseases. Stat Med 2000;19:13-33.

13 Stronks K, Kulu-Glasgow I, Agyemang C. The utility of 'country of birth' for the classification of ethnic groups in health research: the Dutch experience. Ethn Health 2009;14:255-69. 
14 The Netherlands Institute for Social Research (SCP). Statusscores. https://www.scp. nl/Onderzoek/Lopend_onderzoek/A_Z_alle_lopende_onderzoeken/Statusscores (accessed 29 Nov 2016)

15 de Graaf H, Bakker BHW, Wijsen C. A world of difference: The sexual health of LGBT people in the Netherlands, 2013. Utrecht: Rutgers, 2015.

16 Kramer SC, Schmidt AJ, Berg RC, et al. Factors associated with unprotected anal sex with multiple non-steady partners in the past 12 months: results from the European Men-Who-Have-Sex-With-Men Internet Survey (EMIS 2010). BMC Public Health 2016;16:47.

17 Wilkinson A, El-Hayek C, Fairley CK, et al. Incidence and risk factors associated with chlamydia in men who have sex with men: a cohort analysis of Victorian Primary Care Network for Sentinel Surveillance data. Sex Transm Infect 2012;88:319-24.

18 Malek R, Mitchell $H$, Furegato $M$, et al. Contribution of transmission in HIV-positive men who have sex with men to evolving epidemics of sexually transmitted infections in England: an analysis using multiple data sources, 2009-2013. Euro Surveill 2015;20:21093.

19 Guy R, Goller JL, Spelman T, et al. Does the frequency of HIV and STI testing among men who have sex with men in primary care adhere with Australian guidelines? Sex Transm Infect 2010;86:371-6.

20 Katz DA, Dombrowski JC, Swanson F, et al. HIV intertest interval among MSM in King County, Washington. Sex Transm Infect 2013;89:32-7.
21 Frankis J, Goodall L, Clutterbuck D, et al. Regular STI testing amongst men who have sex with men and use social media is suboptimal — a cross-sectional study. Int J STD AIDS. Published Online First: 4 Mar 2016. doi:10.1177/0956462416636780

22 Marcus U, Ort J, Grenz M, et al. Risk factors for HIV and STI diagnosis in a community-based HIV/STI testing and counselling site for men having sex with men (MSM) in a large German city in 2011-2012. BMC Infect Dis 2015;15:14.

23 van Aar F, van Weert $Y$, Spijker R, et al. Partner notification among men who have sex with men and heterosexuals with STI/HIV: different outcomes and challenges. Int J STD AIDS 2015;26:565-73.

24 Op de Coul EL, Warning TD, Koedijk FD, Dutch STI clinics. Sexual behaviour and sexually transmitted infections in sexually transmitted infection clinic attendees in the Netherlands, 2007-2011. Int J STD AIDS 2014;25:40-51.

25 Romero-Severson EO, Alam SJ, Volz EM, et al. Heterogeneity in Number and Type of Sexual Contacts in a Gay Urban Cohort. Stat Commun Infect Dis 2012;4:4.

26 Romero-Severson EO, Volz E, Koopman JS, et al. Dynamic variation in sexual contact rates in a cohort of HIV-negative gay men. Am J Epidemio/ 2015;182:255-62.

27 Gray RT, Hoare A, Prestage GP, et al. Frequent testing of highly sexually active gay men is required to control syphilis. Sex Transm Dis 2010;37:298-305.

28 Fairley CK, Law M, Chen MY. Eradicating syphilis, hepatitis C and HIV in MSM through frequent testing strategies. Curr Opin Infect Dis 2014;27:56-61.

29 Tuite A, Fisman D. Go big or go home: impact of screening coverage on syphilis infection dynamics. Sex Transm Infect 2016;92:49-54. 